\title{
Dhikrullah Vibration as Stimulus of Social Behavior Change
}

\author{
Iskandar ${ }^{1}$, Kusumawati Hatta ${ }^{2}$, Azhar ${ }^{3}$ \\ ${ }^{1}$ Faculty of Islamic Guidance and Conceling, State Islamic Institute of Malikussaleh, Lhokseumawe, \\ Indonesia \\ ${ }^{2}$ Faculty of Islamic Communication, State Islamic University of Ar-Raniry, Banda Aceh, Indonesia \\ ${ }^{3}$ Faculty of Education, State Islamic University of Ar-Raniry, Banda Aceh, Indonesia \\ isibrahm@gmail.com
}

\begin{abstract}
Dhikrullah is a strong single sound stimulus not yet applied as a stimulus to invite alpha wave in the brain as a center of human consciousness. Dhikrullah has been practiced among Muslims for more than a thousand years, but research on the function of dhikrullah as a stimulus to the brain waves as the center of human consciousness has not yet been completed. Chapter 2 of al-Anfal verse 2 and chapter ar-Rad verse 28. This study is an academic response to the foundation of discovering science for social change through dhikrullah. Scientific attention to behavior change through vibration stimuli is still very few. The combined data in this study consisted of qualitative data from 4 respondents in order to find the Dhikrullah model and quantitative data from 10 subjects to obtain dhikrullah stimulus samples on subject brain waves through Electro Encephalo Graf (EEG). The results obtained by EEG encourage dhikrullah as vibrations to be carried out as a stimulus to brain waves. Dhikrullah through the audiotory nerve is able to stimulate the brain to present alpha waves on the subject while running the dhikrullah. All subjects stated the difficulty of feeling calm during and after dhikrullah as a basis for behavior change. This study is new because it uses EEG to prove that dhikrullah vibration can be a stimulus for behavior change. Behavioral reviewers, especially practitioners can use dhikrullah as a stimulus to help humans who want to get change easily and cheaply.
\end{abstract}

Keywords

Dhikrullah; stimulus, brain waves, behavior

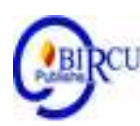

\section{Introduction}

Dhikrullah as a ritual in Islam began to be debated 700 years after the Prophet Muhammad died [1]. According to the Koran the ritual can give effect to the brain, but until now there has not been found studies that explain the effects of dhikrullah stimulus on brain waves as the basis of changes in social social behavior. It is significant to explain the function of Dhikrullah to the wider public because it is related to Muslim rituals. The purpose of this paper is to introduce dhikrullah vibration as a stimulus to brain waves that can influence social behavior.

In principle, this study focuses on sound as a stimulus to brain waves, but the author chose Dhikrullah as the object of study because the word has a unique sound character. Sound will bring up images in the brain, but dhikrullah as the sound of contemplation is different from all words. Dhikrullah will free the brain from various definitions that cover creativity, perception, assumptions, delusions, illusions, hallucinations and contemporary experiences that damage behavior.

Some authors have conducted studies of sound as a stimulus to brain waves and also the sound of influencing social behavior change. The author has summarized some of the 
literature that discusses the function of sound as a stimulus to the brain. This general review of the literature and sources of information used by the author to support the purpose of this paper.

Maquet stated the results of research on the function of sound as a stimulus to the brainstem, forebrain and brain state during sleep. Emotional negative content such as fear can also be caused by certain tone stimuli. Stimulus can also have a positive influence on the brain [2]. Joe Kamiya in 1960 developed biofeedback for the benefit of therapeutic techniques through the technique of controlling alpha rhythm by using tones to show that the brain is able to produce alpha waves. Kamiya's goal is to control states of consciousness through sound stimuli. Robert F. Hink found that in the brain there is a frequency following response phenomenon, in which the brain tends to adjust its frequency to the frequency of sound stimulation from outside.

Brain waves manifest from changes in the level of consciousness. These changes are related to neurons, neurotransmitters, limbic systems, body organs and skin. Quine introduces the term global stimulus to describe the correlation of the sensory experience of the sugar with the mental state of humans. A stimulus experience based on visuals on the retina or hearing on the cochlea. The effect of the stimulus on the retina and cochlea as described by science clearly proves that the stimulus influences human behavior [3]. Quine has not involved stimulus without perception like dhikrullah. The author sees Quine's statement about global stimulus as a signal to find the ultimate stimulus. In the context of the ultimate stimulus, the author considers dhilrullah to be considered.

The state of brain waves is influenced by perception, hallucination, illusion and delusion. Therefore, the state of brain waves shows mental activity as a driver of human behavior. Sound stimulates the brain and the brain influences behavioral changes. Robert W. Proctor wrote in his book about the effects of the phenomenon of stimulus response to sound compatibility as one important discussion because it is related to perception, action, attention and intention. These four elements are closely related to human behavior. Proctor writes about the effect of stimuli which give rise to certain images or circumstances in humans [4] . Unlike the dhikrullah stimulus which frees the brain from various perceptions and assumptions that are material.

Katheryn J. Saunders writes about stimulus control procedures and processes, but it is different from what was done by Joe Kamiya in 1960 in biofeedback research. The discussion is related to the stimulus class which consists of a number of different procedures. Saunders focused on the demonstration of stimulus classes involving examples of stimulus control. As a way of distinguishing stimulus classes from classes that do not involve stimulus control. The discussion emphasizes stimulus experiments in participant groups [5]. If the prayer room in the mosque may be likened to a class, then the mosque becomes the main class that controls stimulus through dhikrullah. Of course the main function of the mosque is not as a center for stimulus control.

The sound in the word Allah is unique and each voice expresses the majesty of each of which is a name for the supreme. James D'Angelo examines the strength of the letters contained in the pronunciation of God. The word Allah consists of only four letters, but there are extensive meanings and secrets of vibrations in the word. In the word of God there are two unique sounds related to God. L sound and AH sound. L's voice in the word Allah is very shaking [6]. The voice of AH in many religions refers to divinity. The L consonant produces a unique vibration. Angelo suggested that the L sound be pronounced in a special format, emphasizing the AL and AH voices. The pronunciation of the name Allah is related to the breath and the pronunciation uses tone. Speak out loud in accordance with the rhythm of AL one beat and LAH two taps [6]. 
The author sees all previous study data supporting the facts about dhikrullah vibration can function as a stimulus to brain waves. The mood of the brain can affect individual behavior. This study is one of the newly approved because it uses EEG to prove dhikrullah vibration can be used as a stimulus to brain waves that influence behavior change.

\section{Research Methods}

The author used qualitative data to find the model of Dhikrullah based on 4 informants in Medan, North Sumatra. Qualitative data were collected with observation, interview and participant. All qualitative data were analyzed by using Dhikrullah comparative models. The Dhikrullah model was used for testing the effects of Dhikrullah vibrations and the effects of hyper ventilation on the brain waves. All subjects were 25 years. Quantitative data to gain samples from 10 subjects through EEG to see the effects of the dhikrullah on human brain awenenes at general hospital Haji Adam Malik, Medan, North Sumatra. The subjects are willing to follow all procedures during recording dhikrullah. EEG results are needed to ensure the influence of dhikrullah on human brain consciousness.

\section{Result and Discussion}

Before Two special verses in the holy Quran which mention dhikrullah effect on human brain waves. Chapter al-Anfal verse 2 and chapter ar-Rad verse 28. Dhikrullah has been practiced among Muslims because they believe in dhikrullah can be used as a stimulus to the brain waves [7].

\subsection{What is Dhikrullah}

Dhikrullah can be done by repeatedly chanting Allah ... Allah ... with the tongue [8]. Therefore, Dhikrullah is the recollection of God [9]. Dhikrullah in the Sufi perspective is the mention of the name of Allah [10]. Dhikrullah can also be done with a single dhikir (al-dhikr al-mufrad), only mentioning Allah ... Allah ... Allah. Scientifically it can be said to mention the name of God, sound energy, audio sonic frequency, healing words, therapeutic waves, touch therapy, strongly vibrated, and cymatic therapy. One form of sound therapy that is not applied through hearing is called sympathetic therapy (cymatic therapy). The therapy uses a device that can send sound waves (sending sound waves) into the body through the skin. This process is said to introduce a healing environment in the body. [11].

Dhikrullah is a voice that has a unique character. The voice is one of the astonishing phenomena besides the colors and shapes of human faces that never end. The initial voice that science has successfully tracked is the Big Bang. The sound itself is included in the study of physics and the implications of sound can be traced through chemistry, mathematics or neuroscience. Because dhikrullah is sound, its existence can be explained through physics and its implications can be explained through chemistry and neuroscience. The congress is that all knowledge can be used to explain Dhikrullah. According to experts, Dhikrullah is the most famous word on earth, the most human being, the most benefit word and mentions 2696 times in the Holy Quran. Dhikrullah has been practiced for more than a thousand years, the name of God has been discussed in the history of Dhikrullah according to the scientific perspective has not been completed. There are three main results obtained by EEG.

\section{a. Dhikrullah Vibrations Produce a Stimulus to Brain Waves}

Dhikrullah starts from the brain [12]. In the left brain there is a temporal lobe which is a place for the wernicke that functions as an area to start the initial process of speech before 
being sent to the broka located in the frontal lobe [13] . Therefore, exploring dhikrullah from a scientific perspective will be related to an explanation of the brain. The brain weighs between 1100 and $2000 \mathrm{~g}$ and contains about 100 billion neurons [14]. The brain functions to connect the micro-nature in human beings with the macro-nature outside of humans. Internally, neurons in the brain can communicate with each other through the emission of electric waves it produces. The brain produces waves that can radiate outward and are able to influence the environment. In the process of interaction, the brain has the potential to receive interference from various waves from outside himself. Disturbances in brain waves will cause the body's control system to not function optimally in controlling the metabolic system and nerves in the body [15].

Although dhikrullah starts from wernicke, the left hemisphere, it is related to the lymbic system that can receive visual and audio stimuli. The limbic system as the location of emotions is located in the center of the brain. The influence of Dhikrullah vibration on the brain also affects the heart, stress, blood quality, body fluid balance and body temperature [16]. The brain as the center of human control, issuing emotional and rational commands related to various other organs in the human body [17]. Because of this, the brain issues dhikrullah's commands, both emotional and rational. Emotional and rational commands are related to human behavior.

Modern studies have proven that sound can be used as alternative energy in the future in accordance with renewable energy. The power produced by sound vibrations when through a medium is called sound energy. Sound energy is a type of mechanical power that is easily recognized through hearing. Sound power is represented visually as waves. According to science, every vibration can produce sound energy in the form of energy waves. Humans are sensitive to sound. Therefore, humans are able to hear and feel the vibrations of sound through the skin, bone conduction, vision, smell, and touch. Through vibrations that are only captured by hearing allows humans to experience a wider range of vibrations. The sound waveform is longitudinal. Humans can produce sound through activities that occur in the vocal cords which are the main components in the sound producer other than the lungs and articulators ( [18].

Sound can influence human behavior. Dossey acknowledged the influence of spiritual symbols and sacred sources, but few scientists used modern science to explain the form of sound to human health. One form of sound therapy that is not applied through hearing is called cymatic therapy. The therapy uses a device to send sound waves into the body through the skin) [10].

Sound pollution can cause interference with the brain and health. Waves will carry energy, both visible and not. Sound waves can carry large amounts of energy. The amplitude of the wave is related to the energy carried by the wave. Strong sound waves have a greater amplitude than weak sound waves. A strong sound can carry enough energy to damage human hearing [19]. The amount of energy contained in a wave follows the amplitude. Sound as an energy that can be heard turned out to benefit many people. Sound engineering for human benefit has succeeded in curing stress, hearing or high blood pressure disorders.

\section{b. Dhikrullah Vibrations Invite Alpha Waves}

Dhikrullah is done five times a day semalan with a duration of between 3 to 5 minutes can increase concentration. Subjects during dhikrullah feel the body becomes lighter because beta waves get stimulus from dhikrullah. Dhikrullah has been proven by EEG to be useful for repairing beta waves as waves that show anxiety and anxiety in humans. Dhikrullah has the opportunity to be used as a therapy for mind disorders, insomnia, reducing epileptic seizures. 
Beta waves usually increase when feeling sleepy, increased mental activity or light sleep [20].

Dhikrullah which is pronounced according to the Mufarridiyah Congregation method can increase beta waves in the frontal lobe, alpha waves in the pariental lobe and ocpital as a sign of mind in a calm state. In contrast to some opinions which state that brain waves cannot be seen at the same time. The results of the study showed that the brain can produce all waves at the same time with different levels. This can occur because during dhikrullah, beta wave activity is stable as a sign of focus on subjects, while alpha waves appear stronger.

Dhikrullah vibration can function as a therapy because it can change consciousness from beta to alpha frequency. These changes cause the physical, cells, glands, organs, and circulatory system to work more optimally. The nervous system will function with a lower stress level and as a result the entire body will be in a relaxed state. Mentally there will be a harmonious psychological balance. Such mental state will free emotions from stress. Spiritually, will experience feelings of freedom and unlimited happiness. Dhikrullah can influence the formation of calm human emotional character.

Dhikrullah can be used to present alpha waves in the brain. By multiplying dhikrullah can produce a large amount of energy and is useful for increasing mental endurance from psychosomatic disorders. According to sound science can be used for therapy by creating alpha waves that influence the brain relax. The alpha waves are connected to mental conditions, so that a person can feel mentally free from various pressures.

Listening to Dhikrullah in a focused way by closing your eyes is needed to produce alpha waves in the brain. When you open your eyes, the alpha wave disappears. Therefore, subjects are guided to remain focused on the name of Allah by making the dhikrullah sound. According to Avery that dhikrullah must be performed resonantly and a sonorous sound will have a strong influence on emotional [21]. Focusing on God's name can influence the EEG results. The ability of humans to hear the name of God is supported by the audiotory system. Dhikrullah by closing the eyes and listening to the name of Allah can be a therapy for oneself as recognized by the modern holistic system. Therefore, based on the EEG's findings, it shows that the benefit of dhikrullah for humans by closing their eyes can bring in alpha waves which give a relaxing effect. Dhikrullah stimulus is proven to be able to present alpha waves in the brain. Alpha waves are states of brain consciousness that are in a state of calm and have a relaxing effect on subjects. Modern science notes that from the brain comes happiness, pleasure, laughter, sadness, pain and tears. The brain is also a place of madness and many mental illnesses [22]. In behavioral psychology behavior must be explained through stimulus and response, ignoring consciousness and mental states.

\section{c. All Subjects Felt Calm During and After Dhikrullah}

Calm feeling during dhikrullah proved by EEG and after based on interview. When energy moves, the media used causes vibrations. This vibration will give various effects to the environment in accordance with the relationship between vibration with the material character that receives the resonance. Therefore, if the frequency, amplitude and resonance in the same direction will produce a harmonious frequency, amplitude and resonance. The harmony will have many effects that can be stated in various terms. The important question is whether power is able to engineer energy for various purposes. In humans, this power is the mind. The mind will direct all energy to fit the desired goal.

That information was first received by the amygdala as the emotional center of the brain before it reached the cortical rational processing site. Therefore, success is driven emotionally. That is why humans respond to something with their emotions first, not intellectually. That is also why, many bad people would think that even then if they want to 
function the hippocampus. Communication should begin first by stimulating the amydala and then the hippocampus. Make a positive influence on the amydala as an opening. Therefore, the relevance of dhikrullah to the amygdala is important as a basis for behavior change [23]

\subsection{Effects of Dhikrullah on the Brain}

The brain is very sensitive to lack of oxygen. The main reason is because the brain uses quite a lot of energy, mainly related to the electrical activity in the brain. The brain needs oxygen to support various activities. Without an adequate supply of oxygen, the brain is unable to work optimally. Therefore, how to breathe has something to do with sending oxygen to the brain. When dhikrullah, breathing activities occur by breathing in and releasing air through the mouth. One breath for just one mention of God's name. Therefore, dhikrullah breathing improves the quality of behavior. Breathing in dhikrullah improves the quality of $\mathrm{O} 2$ exchange with $\mathrm{CO} 2$ in the body.

Humans need to realize that the body moves all the time. The brain requires the large amounts of oxygen provided by the heart's interaction with the lungs, but all organs also need oxygen, kidneys, muscles, even when humans do not do any activity, they continue to need oxygen. Dhikrullah is able to make significant changes to the quality of the breath for health. The view that humans do not need to improve the way they breathe because always breathing is wrong. Many people use their breathing is not optimal. Their breath is so shallow and they hardly provide enough oxygen for all organs of the body. By doing dhikrullah, it can improve the quality of breath because more oxygen enters the body [24]. Be aware that using breathing is effective enough to change stress levels in the brain. Breathe comfortably, easily and imagine your own breathing will bring healing. Starting a breath at the center or in yoga terms called Hara is able to give effect to the abdominal muscles. Oxygen in the breath will spread and soothe all parts of the body that are tense. That is why the touch of oxygen on dhikrullah can increase feelings of relaxation during dhikrullah on subjects [23] .

\section{a. Amygdala}

Dhikrullah relationship with the amygdala as the center of human emotions in the Southeast Asian region and also the Islamic world in general has not received a broad response, whereas in the West the problem of vibrational relations with emotions has long been ongoing. The amygdala is the nerve collections in the brain that play a role in processing and reacting to emotions [25]. Amygdala terror explains the dynamics of emotions in humans. It controls human behavior when facing emotional situations. He accepts the stimulation of visual and audio as a motivating factor for emotional potential [26]. Amygdala conditions affect the process of hormone production, circulatory system, breathing, and fear (Vicent Di Mario, 2016: 130). Neuroscience explains that the amygdala plays a role in presenting the feelings of fear and anxiety in the brain [27]. Amygdala is also involved in the process of helping anatomical adjustment to obtain physiological responses, increased blood pressure, breathing and facial expressions of fear. Amygdala has a relationship with hearing [28] . Therefore, listening to dhikrullah can be an emotional stimulus to the amydala which can shed tears when crying. Rude words will be stored in emotional memory for a long time.

Emotional development in the amygdala is influenced by a number of complex and thoughtful experiences. In a depressed condition, the amygdala sends a message to the endocrine glands to secrete a number of chemicals that begin with the release of CRF (corticotrophin-releasing factor) and end with a flood of cartisol hormones. The buildup makes the amygdala a very sensitive detonator, so that it can react more dominantly than rational consideration. According to neuroscientist Joseph LeDoux, the amygdala in the human brain functions as a storage place for memories related to emotions. The amygdala 
will react according to the emotional experience it has experienced, whether it is a pleasant experience or not. In individuals whose amygdala is disturbed they become less interested in other individuals and the personality condition becomes passive accompanied by their recognition of the emotions of an event being very minimal (affective blindness).

Amygdala will issue an emotional reaction to the stimulus received in accordance with the emotional memory of an event or object. The emotional data processing center in the brain will fill new data or allow the data to affect the amygdala. Emotions can be understood as individual turmoil accompanied by a response to a stimulus that contains a basic need where if those needs can be met, then feel happy and if not going to get angry. Amygdala which occupies the main position as a memory element that records emotional experiences in the limbic system when the process of interaction occurs internally and externally in humans continues to get the attention of neuroscience experts [29]. They argue that according to a number of studies conducted on the amygdala, it shows a significant role in activating the emotional system when interactions occur. Experts' perspectives on the position of the amygdala can be seen in the opinion of Lisa Feldman who has conducted studies on the amygdala with the result that the size of the amygdala is related to the ability of adult socialization on a complex scale [30]. Whereas the amygdala in the neuroteological view mentioned anti-rationalist religious behavior caused by very strong neurological activity in a part of the brain from the limbic system. Paul Sanberg, Director of the University of South Florida's Center for Excellence for Aging and Brain Repair, found that the amygdala also has a role to play in our fears, emotions and even seizures.

David a bourne explains that there is a relationship between the amygdala and the cortex. Age 12 years is more dominant to experience development in the structure of the amygdala, while the cortex develops at the age of 20 years, therefore the amygdala develops earlier than the cortex. Caroline leaf explained in Who Switched Off My Brain that people who think well will experience an increase in the number of bonds of each neuron and dendrite in the brain more and more organized, while the brain that thinks negatively tends to damage brain cells. This damage is not only caused by stress and mental disorders, but also external factors due to hearing harsh words and negative influences from the environment.The aspect of pronunciation is that which explains the procedure of mention dhikrullah that can affect the amygdala. The internal aspect of intention can have implications for changes in brain waves as a sign of change in emotions. The frontal lobe located in front of the brain functions to direct behavior and is responsible for deciding good or bad things [31] .

\section{b. Dhikrullah against Amygdala}

The sound produced by someone is able to give effect to the nervous system in themselves and also others. In every sound contained various feelings. Sound is one of the main aspects to get to know a person's character and emotional state, whether sad or happy. Individual characters can be categorized by listening to the level of frequency, speed, and sound strength, spoken language, how to sing or the vocals used. If the sound has a different character from one person to another, then likewise the brain waves have different characters from one person to another.

Humans have two memories, i.e. amygdala and hippocampus. Both of these memories are found in the limbic system [32]. The hippocampus is a memory for intellectual processes that have relevance to the senses, especially hearing dhikrullah. The limbic system stores a lot of information and functions to control the human consciousness system [33]. Whereas the throne girus functions to connect between the regulator of emotions in the limbic system with cognitive abilities in the cerebral cortex. The mammary regulates the movements of the tongue and esophagus when dhikrullah [34] . Amygdala stores emotional memory and 
regulates human behavior when faced with certain circumstances and also receives stimulation from visual and audio as a potential motivating factor for emotions [22]. Amygdala affects hormone production, blood circulation, breathing, and digestion [34]. Because dhikrullah affects brain waves, dhikrullah's influence on brain waves affects the amygdala. The condition of the amygdala has an effect on correcting the way of breathing. Previous studies about personality differences are influenced by breathing patterns when individuals are in a state of stress. The results showed that the level of individual anxiety affects the frequency of breathing [28].

Dhikrullah is able to arrange the limbic system, lobes in the head, heart work, blood circulation and lungs which are important elements as determinants of psychological health. When doing dhikrullah, bio-electric flow in the auditory nerve, memory, amygdala and hippocampus in the brain increases due to the active involvement of these parts in the dhikrullah process. Likewise, if dhikrullah is done repeatedly it will cause the bio-electric flow to become more active. Active nerves will affect other nerve groups to be active, so that the brain becomes active as a whole, thus producing waves caused by dhikrullah. According to the Koran, the power of dhikrullah is able to bring someone to glory (Q. S 62: 10). These findings prove that scientifically, dhikrullah repeatedly will improve brain health [35] .

Sound waves, both during speaking and laughing are expressions of human emotions themselves. Dhikrullah is able to influence the brain and feelings. Dhikrullah harmonizes brain waves as a mental signal to be in a stable state. There seems to be a close relationship between a stable mental and stable brain waves in forming stable behavior. The special aspect of the human voice is that there is a cathartic function, which is able to eliminate various influences on the mind that can cause interference with emotions. Therefore, dhikrullah by following the principles of science is proven to be able to produce real implications that affect the amygdala as a driver of behavior.

\section{Conclusion}

Dhikrullah has long been felt to provide calm and EEG results prove that dhikrullah can be a stimulus that can affect brain waves. The stimulus influences the activity of neurons and the limbic system in the brain. Changes in the state of neurons and the limbic system affect brain waves. Changes in brain waves as a manifestation of changes in consciousness. Changes in brain consciousness affect perception, hallucination, illusion and delusion. Therefore, the state of brain waves shows changes in thoughts, feelings, and emotions. Sound is proven to stimulate the brain and brain through the modula oblongata to determine behavior change. Therefore, dhikrullah as a voice is able to influence changes in individual behavior. Changes in individual behavior are the basis of changes in social behavior. That is why dhikrullah can influence social behavior.

\section{Acknowledgment}

Thanks to Mr. Sukirman, EEG specialist Neurology Departemnet at Adam Malik Hospital, Medan, Indonesia. 


\section{References}

[1] S. Hadzrullathfi and S. Omar, "the Ritual Practices of the Naqshbandiyya-Khlidiyya Order in the Ritual Practices of the Naqshbandiyya-Kh 1 Lidiyya Order in Contemporary Malaysia," no. January 2012, 2017.

[2] P. Maquet, "The role of sleep in learning and memory," Science (80-. )., vol. 294, no. 5544, 2001.

[3] W. V. Quine, From Stimulus to Science. .

[4] Robert W. Proctor, "Stimulus Response Compabilty Priciples., pp. 165-168, 2006.

[5] T. R. Z. and P. M. S. (Eds.), "Stimulus Class Formation in Humans and Animals," 1996.

[6] J. D'Angelo, "The healing power of the human voice : mantras, chants, and seed sounds for health and harmony" 2005.

[7] Qusyairy, Ar-Risalah Al-Qusyairiah, pp 121, 1999

[8] J. Renard, The A to Z of Sufism, vol. 91, no. 5. 2009.

[9] C. R. and LeifStenberg, "Sufism Today Heritage and Tradition in the Global Community."

[10] William C. Chittick. 2008. The Essential Seyyed Hossein Nasr. Canada: World Wisdom.

[11] Laurie J. Fundukian. 2009. The Gale Encyclopedia of Mental Health. London: Gale Group

[12] Ahlsén, Elisabeth. 2006. Introduction to Neurolinguistics. USA: John Benjamins B.V

[13] Dale Purves. 2004. Neurosciences. U.S.A: Sinauer Associates

[14] David L. Clark. 2005. The Brain and Behavior An Introduction to Behavioral Neuroanatomy. UK: Cambridge University

[15] Laurie J. F. 2008. The Gale Encyclopedia Of Mental Health. London: The Gale Group

[16] Kara Rogers. 2011. The Brain and The Nervous System. New York: Britannica Educational Publishing

[17] David A. Leeming. 2010. Encyclopedia of Psychology and Religion. USA: Sringer

[18] Barbara Montgomery Dossey. 2005. Holistic nursing: a handbook for practice. United States of America: Malloy, Inc

[19] Willian O.Tatum, "Handbook of EEG Interpretation", pp 29. 2008

[20] John S. Avery, “Hyperspherical Harmonics and Generalized Sturmians” pp. 94, 2002

[21] Michael R. Trimble MD, The Soul in the Brain: The Cerebral Basis of Language, Art, and Belief," pp.25, 2007

[22] David Singleton, "Language and the Lexicon: An Introduction, “ 2000

[23] Alexa Fleckenstein, Roanne Weisman "Health20: Tap into the Healing Powers of Water to Fight Disease, Look Younger, and Feel Your Best" pp 107, 2007

[24] Barbara Rubin.“ Healing Crisis and Trauma with Mind, Body, and Spirit "pp 135, 2006

[25] Paul J.Whale, Elizabeth A. Phelps 2009 "The Human Amygdala" pp 16,

[26] V. S. Ramachandran. 2002. Encyclopedia of Human Brain. USA: Academic Press

[27] Barbara Ferry. 2012. The Amygdala A Discrete Multitasking Manager. Croatia: InTech

[28] Atsuko masuda. 2004. Post-Genomic Perspectives in Modeling and Control of Breathing. New York: Plenum Publishers

[29] Achmad Mubarok. 2001. The Quranic. Psychology. Jakarta: Pustaka Firdaus

[30] Dadang Hawari. 1997. Pray dan Ddhikrullah. Jakarta: Dana Bakti Primayasa

[31] Stephen P. Salloway. 2001. The Frontal Lobes and Neuropsychiatric Illness. USA: American Psychiatric Publishing.

[32] Rndall C. O'Relly and Yuko Muna Computational Explorations in Cognitive Neuroscience: Understanding the Mind by Simulating the Brain, pp 212, 2000.

[33] Carol Turkington” The Encyclopedia of the Brain and Brain Disorders” pp 64, 2002

[34] Michael A. Arbib. 2003. The Handbook Of Brain Theory And Neural Networks.

[35] Bonnie Strickland. 2001. The gale Encyclopedia Of Psychology. Second Edition. The United States Of America: Farmington Hills. 